\title{
The Specificity of General Human Capital: Evidence from College Major Choice
}

\author{
Josh Kinsler \\ Ronni Pavan \\ University of Rochester
}

November 14, 2011

*PRELIMINARY AND INCOMPLETE - PLEASE DO NOT CITE OR DISTRIBUTE

\section{Introduction}

Workers with a college degree earn significantly higher wages than high school graduates. This fact has generated a vast literature both to estimate the true extent of the return to schooling and also to understand the factors that influence the choice of schooling quantity. An interesting feature that has been largely neglected in this literature is that college graduates with a science or business related degree earn up to $25 \%$ larger wages than other college graduates. ${ }^{1}$ The wage gap across college majors is surprisingly large given that there are no direct monetary costs associated with the choice of college major. Yet, despite the gap in earnings, relatively few students choose to major in either business or science.

In this paper we develop a model to estimate the true return to college major and to understand why students appear to give up part of their earning potential by selecting less profitable majors. Our modeling approach is motivated in part by the empirical finding that we also present in this paper. Individuals who work in a job related to their major field of study earn significantly higher wages than those working in jobs unrelated to their major and this gap is particularly acute for math and science majors. ${ }^{2}$ Although wage differences related

\footnotetext{
${ }^{1}$ See Section 2.

${ }^{2}$ See Section 2 for detailed analysis.
} 
to the applicability of one's major may be driven by selection, the patterns we observe in the data seem to suggest that a portion of the human capital obtained during college is not productive across all jobs. Thus, schooling might not only represent an investment in general human capital, as in Mincer (1958), but also an investment in some sort of specific human capital.

The idea that a portion of a worker's accumulated human capital is not universally applicable across all jobs has been incorporated into career and occupational choice models for decades. ${ }^{3}$ Yet, in most of these models, the only channel through which workers accumulate specific human capital is through work experience. Schooling is generally treated as a measure of general human capital, and can be applied across all occupations, industries, and tasks. ${ }^{4}$ In this paper we instead allow the human capital that is accumulated while in college to be both general and specific to the major field of study that the student selected.

Understanding the specificity of schooling human capital can help shed light on both the true returns to college major and the forces underlying college major choice. Much of the previous literature on college major choice has focused on the impacts of preferences while in college and expected income on field of study. ${ }^{5}$ By incorporating human capital specificity along with preferences and uncertainty over future labor market outcomes, we can better understand the determinants of major choice, i.e uncertainty can lead risk-averse students to choose "safer" majors. ${ }^{6}$ The fact that wages respond more to whether the job is related to

\footnotetext{
${ }^{3}$ Becker (1962) and Oi (1962) originally developed the notion of firm-specific human capital. Over time, the idea was expanded to include occupation, industry, and location specific human capital. Prominent examples include McCall (1990), Parent (2000), Neal (1995), Pavan (2011), and Kennan and Walker (2011). Recent papers, such as Poletaev and Robinson (2008), Gathmann and Schnberg (2010), and Yamaguchi (2011) have focused more on task specific human capital, stressing that what matters in not the job's label, but the actual tasks a job employs.

${ }^{4}$ Examples include Keane and Wolpin (1997) and Sullivan (2010).

${ }^{5}$ Arcidiacono (2004) and Beffy et al. (2009) estimate the impact of preferences and expected income on major choice. Both papers allow for observed and unobserved heterogeneity across students that affects both schooling choices and wages.

${ }^{6}$ The idea that risk may play a role in individual major choices has also been incorporated in a number of recent papers. Altonji (1993) and Montmarquette et al. (2002) incorporate the risk of failing out of school for a given major when calculating the future expected earnings for each choice. Nielsen and Vissing-Jorgensen (2010) estimate flexible lifecycle wage profiles associated with 50 different higher education fields using detailed Danish data. They find that majors with higher variability in earnings arising from both permanent and
} 
the field of study for science majors as compared to all other majors points to a higher level of occupational risk in the science field. This type of risk may help explain why there are so few science related majors even though wages tend to be much larger for those workers.

Identifying the mechanisms that govern students' major choices is critical for designing policies aimed at influencing those decisions. Recently developed programs in the U.S., such as the National Science and Mathematics Access to Retain Talent Grant (SMART) and the Science, Technology, Engineering, and Mathematics Expansion Program (STEP), indicate a strong desire among policy makers to increase the share of college students entering technical fields. ${ }^{7}$ The success of these and future programs will hinge on whether the policies target the key mechanisms driving major choices.

In addition to its impact on major choice, the specificity of schooling human capital has important implications for the labor market. Specific human capital is not applicable across all types of jobs, implying that the expected value of a particular field of study is heavily dependent on the occupational structure in the economy. As this structure changes, we would expect schooling outcomes beyond attainment to respond. In addition, for those individuals already in the labor market the specificity of their schooling human capital can make job displacement or re-training quite costly. Taken to the extreme, the wage changes that often accompany occupation, location, or task changes could reflect in part the specificity of an individual's schooling human capital as opposed to human capital obtained while in the labor market. The specificity of education can also have a direct impact on wage inequality. As an example, the aforementioned SMART program incentivizes students to choose math and science degree fields. If the human capital developed in these fields is quite specific, then inequality in the labor market may rise since not all of these students are likely to work in jobs that employ these skills.

To investigate the specificity of human capital through schooling we turn to the Baccalaureate and Beyond Longitudinal Study $(B \& B)$. The B\&B consists of a representative sample transitory shocks are less attractive.

${ }^{7}$ The rationale for these programs is that policy makers believe that graduates who obtain a degree in a technical field generate a positive externality in the broader economy. Murphy et al. (1991) provides support for this belief. The focus on math and science skills is not limited to the higher educations sector. The National Math and Science Initiative is another recently developed program that focuses strictly on primary and secondary school students. 
of 11,192 graduating seniors drawn from the 1993 National Postsecondary Student Aid Study (NPSAS). This group of college graduates is subsequently surveyed in 1994, 1997, and 2003, providing detailed information on schooling and labor market outcomes. The B\&B has two key features that make it ideal for the understanding the specificity of human capital through schooling. First, we are able to construct major specific grade point averages even for fields which students decided not to pursue. This gives us a window into what a student's outcomes might have looked like had they chosen a different major. Second, individuals are asked whether their job is related to their field of study. We use responses to this question as an indicator for whether an individual is utilizing the specific human capital accumulated through their field of study. Our interpretation of this variable is consistent with our reduced-form result that individuals who work in related jobs earn significantly higher wages.

Using our reduced-form findings as a guide, we then develop a structural human capital model in order to disentangle the various factors influencing major choice. Our framework and identification strategy is related to Carneiro et al. (2003), as it utilizes a similar factorbased structure. There are two types of unobserved human capital in our model, general and subject-specific. Students enter college with a baseline level of general human capital, which we distinguish between math and verbal human capital. Education is then responsible for a major-specific increase in this vector of general human capital. On top of this, students also develop a certain amount of specific human capital as a result of schooling. Upon exiting college, individuals enter the labor market and choose the type of work to pursue. Individuals bring to the labor market their general human capital and the subject-specific human capital for the chosen major. Wages then depend on an individual's level of general and subjectspecific human capital and the type of job selected. While general human capital affects wages in all jobs, its importance is allowed to vary across different occupations. The effect of specific human capital also depends on the occupation chosen, but it is different from zero only if the job is related to the field of study.

The remainder of the paper is as follows. Section 2 describes the B\&B data in detail and provides the reduced-form evidence of the specificity of human capital through schooling. In section 3 we describe our model of major and occupational choice and discuss identification. Section 4 discusses estimation and presents the structural estimates along with some simple validation exercises. In section 5 we perform several counterfactual experiments to understand 
the relative importance of the various mechanisms driving major choices. Section 6 concludes.

\section{Data and Reduced-Form Analysis}

We use data from the first cohort of the B\&B to investigate the links between human capital, major choice, occupational choice, and wages. The initial B\&B cohort consists of a representative sample of 11,192 graduating seniors drawn from the 1993 National Postsecondary Student Aid Study (NPSAS). This group of college graduates is subsequently surveyed in 1994, 1997, and 2003. The original NPSAS data along with the follow up B\&B surveys allow us to construct detailed information on students' backgrounds, schooling outcomes, and labor market outcomes. While the sample is representative, the B\&B provide sampling weights, which we use in both the descriptive and structural analysis. Additional details regarding the sample are provided below.

\subsection{Student Background and Schooling Data}

The 1993 NPSAS and 1994 wave of the B\&B collected detailed background data on each student. Using this data we are able to construct measures of respondent race, gender, and age. We limit the sample to males to avoid the complications fertility expectations have on female human capital accumulation, occupational choice, and labor supply. This reduces the number of students to 4,834. In addition, there are a significant amount of graduating seniors in 1993 who are older than 30. Older graduates tend to have lower (higher) math (verbal) SAT scores, choose business majors more often, make different occupation choices, and earn more than their fellow graduates who are significantly younger. These students likely also differ on unobserved dimensions. In order to keep a relatively homogenous sample we decided to drop anyone above the age of 30 in 1993, reducing the sample to 4,264 individuals. In addition, any individual with missing parental information or missing SAT is excluded from the sample, resulting in a final sample of 2,476 individuals. $^{8}$

Detailed data on college major choice, as well as major specific GPA are readily available.

\footnotetext{
${ }^{8}$ Many individuals in our sample take the ACT rather than the SAT. We are unable to incorporate these individuals since only the composite ACT score is available and in our empirical analysis we treat separately the SAT math test from the SAT verbal test.
} 
In order to keep the model tractable, we collapse major choice into three broad categories: business, science, and other. The aggregate business major includes fields such as economics, accounting, and general business. The science major includes engineering, the physical and natural sciences, and computer science. All remaining fields, such as social sciences, education, psychology, humanities, etc., fall into the other category.

Through student transcript data, information regarding student participation and performance across the various majors is available. As an example, the B\&B constructs the total number of credits and associated GPA in all humanities type courses. Credits and GPA are also available for business, social science, science and engineering, education, math, and foreign language courses, among others. Using these disaggregated variables we can construct individual specific GPA measures for each of our broad major categories. Note that we can only construct these measures if a student ever took a course in one of these subjects. GPA measures for business, science, and other are available for $45 \%, 95 \%$, and $98 \%$ of our sample respectively.

In survey years 1994, 1997, and 2003, each individual is asked about post-BA degree receipt. For tractability, we treat all graduate degrees identically and we do not allow individuals to switch their major at this point..$^{9}$ This is not a severe limitation as $70 \%$ of the individuals who eventually obtain a graduate degree choose a graduate field of study that falls in the same broad major category as their undergraduate field of study.

Table 1 provides basic summary statistics describing schooling outcomes. Overall we see that science and business majors account for approximately $50 \%$ of the sample, with students split rather evenly across the two categories. A quarter of the sample eventually obtains some post-graduate degree. When we examine the characteristics of the students across each major significant differences appear. Science majors have higher SAT Math and Verbal scores than either the business or residual group. In addition their science GPA is also significantly higher. Note that both business and other majors take a significant amount of science credits, approximately 20 and 18 respectively. Across fields, GPA is always highest on average for those who chose to major in that field. This likely reflects both selection and the accumulation of subject-specific human capital. Finally, across majors there also appear to be important

\footnotetext{
${ }^{9}$ Note that if an individual reports obtaining a graduate degree by 1994, we utilize the graduate degree major. This occurs for 31 individuals.
} 
differences in family background. Individuals who major in science are more likely to come from lower income households, and households where both parents are foreign born.

\subsection{Labor Market Data}

In survey years 1994 and 1997, respondents were asked about their primary employment during the month of April. ${ }^{10}$ In 2003, respondents were asked about their current job. Across all surveys, individuals provided information regarding their hours, wages, type of occupation, and whether their job is related to their field of study.

Individuals can report wages either hourly, daily, weekly, monthly, or annually. We convert all wages to full-time yearly equivalents for those individuals who report working at least 30 hours per week. For anyone working fewer than 30 hours per week, we treat their annual salary as missing, since we do not model labor supply explicitly. All salaries are measured in $2000 \$$.

Individuals report working in one of 40 occupations in 1994 and 1997, and can choose from 49 occupations in 2003. We collapse these detailed occupations into three broad classifications, blue, pink, and white collar. The general breakdown into the three occupational groups is as follows. Blue collar occupations include jobs that tend to rely on manual labor, less academic preparation, and a set of skills learned largely on the job. Examples include farmers, mechanics, salesman, lab technician, and computer equipment operator. Occupations are classified as pink collar if the job is historically associated with female workers and tend to require less professional training as compared to white collar jobs. Examples include nurses, teachers, secretaries, and clerical workers. Finally, white collar occupations are those that typically consist of salaried professionals who perform tasks that are less physically intensive as compared to blue collar workers. Examples include financial service professionals, lawyers, doctors, engineers, and scientists. ${ }^{11}$

For the 1994 and 1997 surveys, a job is defined as being related to an individual's field of study if the respondent reported that the April job was either closely or somewhat related to their field of study. In 2003, the relationship question is altered slightly. A respondent is

\footnotetext{
${ }^{10}$ Note that in 1994, individuals were also asked about their primary job. When possible, missing information for the April job is replaced with information from the primary job.

${ }^{11}$ Lee and Wolpin (2006) utilize a similar classification system.
} 
considered to be working in a job related to their field of study if their undergraduate education is very important in their current job or if their graduate education is very important in their current job and the respondent reports obtaining a graduate degree. Because of the change in the wording of the question, if an individual reports being in the same job as they were in 1997, we use the relationship variable from 1997. Approximately $13 \%$ of the valid relationship entries in 2003 are changed as a result. If the variables that contain information about the occupation and whether the job is related to the field of study are missing, to the greatest extent possible we use information from the subsequent surveys to fill it in. If the respondent reports starting the current job prior to the previous survey, we replace any missing occupation and relationship variables in the previous survey with their current values.

Table 2 provides summary statistics for the labor market outcomes for the sample as a whole and by major choice. Overall, we see that white collar occupations are chosen most often, which is not surprising given that we are looking at a sample of college graduates. More important is that annual salary is significantly different according to whether an individual is working in a job that is related to their field of study. This difference could reflect sorting, meaning that higher ability individuals are more likely to work in a related job, or it could reflect the idea that subject-specific human capital is not priced when it is not utilized.

Looking at labor market outcomes across fields of study indicate striking differences in outcomes. Business and science majors are significantly more likely to work in white collar jobs relative to the residual group. Not surprisingly, this also translates into significant differences in salaries across the groups. However, the most striking fact that emerges when we break down outcomes across fields is the huge impact that working in a related job has on the salary of science majors. Science majors who work in a job related to their field of study earn close to a $30 \%$ premium relative to science majors who work in an unrelated job. The gaps for business and the residual major are only $3 \%$ and $11 \%$ respectively. Again, this could reflect sorting, varying prices of human capital, or potentially issues with aggregation.

\subsection{Exogenous shifters}

For the estimation of the structural model we construct a series of variables that are assumed to be exogenous to the model. Merging information from the Integrated Postsecondary Education Data System (IPEDS), we link each student to the share of students in each major in his 
graduating college. Using the $\mathrm{BB}$ we also construct state specific deviations with respect to the national average of 1) share of workers with a graduate degree, 2) shares of workers in each occupation, 3) share of workers working or not in a related job, 3) shares of individuals choosing each major, 4) average wage for each major, 5) average wage for each occupation, 6) average wage for workers with a graduate degree and 7) average wage for workers with a related job. Although agents do move across states for economic reasons Kennan and Walker (2011), in our model we assume that geographical location is exogenous. This assumption is mitigated by the fact that $75 \%$ of the individuals in our sample live in the same state in which their parents lived in 1993 or in the same state as their college.

\subsection{Reduced-Form Evidence of the Specificity of Schooling Human Capital}

Table 2 illustrates that not only do wages vary considerably across college major, but also within major according to whether an individual works in a related job. While these patterns are consistent with heterogenous returns to college through major choice and the presence of subject-specific human capital, sorting or aggregation bias introduced by our course characterization of occupation and majors could also rationalize the data. In this section we perform some simple reduced form analysis to shed light on the underlying mechanisms that drive the observed patterns and to help motivate our modeling choices regarding human capital, major, and occupational choice.

The wage differentials across major evident in the summary statistics do not appear to be driven entirely by differences in observed math and verbal ability. Table 3 illustrates that business and science majors earn approximately $20 \%$ more than individuals who choose to major in the residual category, conditional on SAT scores, and major specific GPA. The last two columns show that the estimated major returns are not sensitive to how we calculate income within our sample, nor to the $\mathrm{B} \& \mathrm{~B}$ sample in general. The estimated returns to major using a similarly constructed sample from the National Longitudinal Survey of Youth (NLSY79) are almost identical to our estimates. ${ }^{12}$

The estimated returns to major in Table 3 are similar to the results in Arcidiacono (2004) since we do not account for differences in career paths across majors. Table 4 examines

\footnotetext{
${ }^{12}$ The main differences between the two sample are that the NLSY79 contains an older cohort - between 14 and 22 years old in 1979, and that in the NLSY79 workers are observed for 30 years, from 1979 to 2008.
} 
how the wage impact of major changes when we account for occupational choice. The first column replicates the analysis when we ignore occupation. The second column includes dummy variables indicating whether an individual works in a pink or white collar job. Individuals who work in white (pink) collar jobs tend to earn more (less) than those working in blue collar jobs. Note that $43 \%$ of our sample switches occupation at some point between 1994 and 2003 . This percentage rises to $56 \%$ when we consider only those individuals who are never missing occupation. Across majors, switchers are most likely to come from the business major, but $35 \%$ of science majors switch at least once.

More importantly, Table 4 illustrates that the returns to major drop significantly once we account for occupation. This suggests that sorting into occupations varies across major types, as we already saw in Table 2. What we can't determine from this table is the extent to which this is simply the result of sorting on unobservables or the fact that the returns to major vary across occupations. The final column in Table 4 allows for a more detailed categorization of occupation. The results indicate that most of the interaction between major and occupation choice is captured by the three broad occupational groups.

In addition to occupation, the $\mathrm{B} \& \mathrm{~B}$ contains direct information on whether the specific job within the occupation is related to the worker's field of study. In Table 5 we look at the relationship between this variable and the field of study of a worker. Although the resulting patterns could be generated by the presence of sorting on unobservables, we interpret these regressions as potential evidence of the presence of subject-specific human capital. In the first column we note that, even after controlling for observable measures of general and specific human capital using SAT and GPA, wages are significantly larger in jobs that are related to the field of study, and this relationship is significantly stronger for science majors. In the next column we show that this pattern is not generated by our aggregation of majors as we include dummies for more disaggregated major codes. The importance of the job's relationship with the field of study decreases significantly but not completely when we include occupational controls and/or individual fixed effects, proving again that sorting across majors and across occupations can help explain the relationship between wages and labor market outcomes.

Table 6 digs deeper into the wage returns associated with working in a job related to the field of study and examines whether our noisy measures of specific human capital, the GPA's, actually contain useful information. The first three columns of Table 6 investigate how the 
returns to working in a related job vary with our observed measures of human capital. The results indicate that the returns to subject-specific human capital, as measure by major specific GPA, increase significantly when working in a related job. Neither SAT math or non-major GPA show a similar pattern. This is consistent with a model where general human capital is valued in all jobs, but subject specific human capital is only priced in related jobs. The final two columns of Table 6 look at wage changes as individuals move in and out of related jobs. Individuals who move into a related job obtain a significant increase in wage, and this is particularly true for science majors. Individuals who exit related jobs see little change. Movements across job types is consistent with this wage pattern, as individuals are much more likely to move into a related job than move out. The fact that not everyone starts working in a related job but many eventually move-in suggests that it may be difficult to obtain one of these jobs.

It is clear that no definitive conclusions can be drawn from the results in this section since SAT and GPA are noisy measures of student ability. Thus, we cannot rule out the possibility that the important patterns we find in the reduced-form are either inflated or attenuated by the presence of sorting on unobservables. For this reason, we present and then estimate a model that can account for the presence of such unobservable components.

\section{The Model}

Agents begin their life in college, before deciding their major field of study. After choosing a major and finishing college they enter the labor market. Their labor market history is divided into three time periods, given that in our data set we observe only three observations per individual. The first period (1994) lasts three years, the second period (1997) lasts six years and the last period (2003) lasts until retirement, i.e. $T-9$ years. After working $T$ years, individuals retire for $T_{R}$ years. We assume that there is a finite number of occupations and that within these occupations jobs can be related or not to the field of study of the agent.

\subsection{Human Capitals and Returns to College}

Individuals are characterized by two sets of human capitals, general (math and verbal) and subject specific. The general human capitals are always productive in the labor market, no 
matter which job is chosen. In contrast, the specific human capitals are productive only in a job that is directly related to the field of study of the agent.

When the individual starts his life, he is endowed with a vector of general human capitals. These human capitals are drawn from a joint distribution $F_{g}$ and are possibly correlated with each other:

$$
H_{0}^{g}=\left(H_{0}^{m}, H_{0}^{v}\right) \sim F_{g}\left(H_{0}^{g}\right)
$$

The individual is also endowed with a vector of "potential" subject specific human capital drawn from i.i.d. distributions: $H_{0}^{f} \sim F_{f}\left(H_{0}^{f}\right)$ where $f=\{1, . ., F\} .{ }^{13}$

While in college, a student must choose his major field of study. We denote the chosen field of study by $f^{*}$, but use $f$ to indicate field of study more generally. The consequences of major choice in terms of human capital accumulation are two-fold. First, the student experiences a return to major choice in terms of general human capital:

$$
H_{1}^{j}=H_{0}^{j}+\mu_{1}^{j, f^{*}}+\rho_{1}^{j, f^{*}}\left(H_{0}^{j}-\mu^{j}\right)
$$

where $j=\{m, v\}$ and $\mu^{j}$ is the unconditional mean of $H_{0}^{j}$. Note that the general human capital returns depend on the chosen major, $f^{*}$. We allow for heterogeneous returns to college for general human capital, i.e. the evolution of general human capital differs across individuals endowed with different initial stocks. This feature is one potential source of sorting in our model. Second, by selecting a major an individual is also selecting the subject specific human capital to bring to the labor market. The realized (rather than potential) specific human capital is then :

$$
H_{1}^{f^{*}}=\mu_{1}^{f^{*}}+H_{0}^{f^{*}}
$$

if $f=f^{*}$ and zero otherwise. Notice that we allow for an endogenous accumulation of the specific human capital for the chosen field of study.

\subsection{The wage}

Once in the labor market, individuals receive a wage that depends on the post-schooling human capitals, the chosen occupation and on whether the particular job within the occupation is

\footnotetext{
${ }^{13}$ The specific human capital can be allowed to be correlated with the general human capital but for simplicity in this version we do not consider this possibility.
} 
directly related to the field of study of the worker:

$$
\ln w_{t}=p_{o}^{m} H_{t}^{m}+p_{o}^{v} H_{t}^{v}+p_{o}^{f^{*}} H_{t}^{f^{*}} \times 1\left(r_{t}=1\right)+D_{t}+G_{t}^{f^{*}}+\lambda^{Z} Z_{w t} .
$$

The subscript $t$ indicates calendar time, $o=\{1, . ., O\}$ is the occupation chosen, and the variable $r_{t}$ is equal to 1 if the job is related to the studies of the individual. Although it is reasonable to expect that human capital evolves once in the labor market as a result of accrued experience and/or post-secondary education investment, we assume that human capital remains constant since we have relatively few wage observations in the time dimension.

Thus, $H_{t}^{j}=H_{1}^{j} \forall j$. However, in order to allow for the fact that wages increase both with time and the acquisition of a graduate degree, we allow for a time dummy $D_{t}$ and a graduate degree dummy $G_{t}^{f^{*}}$ that depends on the undergraduate field of study. The econometrician observes $\ln w_{t}^{o b s}=\ln w_{t}+\epsilon_{t}$, where $\epsilon_{t} \sim F_{\epsilon}(\cdot)$. Notice that we also allow wages to depend on a vector of exogenous controls $Z_{w t}$. In the empirical implementation we construct three variables for the state-specific variation from the national average wage for workers with the same major, occupation or relatedness.

\subsection{The Measurement Equations and the Learning}

A crucial component of our empirical analysis is the presence of measurement equations. These measurements allow the econometrician to have a direct, although imperfect, look at the individual's human capitals. The math and verbal SATs are taken prior to starting college and therefore are useful for identifying the math and verbal human capital prior to choosing a college major. We assume that the math test is a function of the math human capital while the verbal test is a function of the verbal human capital:

$$
\begin{gathered}
S A T_{m}=\eta_{c}^{m}+\eta^{m}\left(H_{0}^{m}+u_{m}\right), \\
S A T_{v}=\eta_{c}^{v}+\eta^{v}\left(H_{0}^{v}+u_{v}\right) .
\end{gathered}
$$

The residual components $u_{m}$ and $u_{v}$ can be interpreted not only as measurement error but also as scholastic abilities that are not transferred to the labor market. We allow these components to have a non-zero covariance. In our data we also observe subject specific GPAs. We assume the subject-specific GPAs are functions of the post-schooling general human capitals, and the post-schooling specific human capital associated with each field. Note that for 
subjects not chosen, the post schooling subject specific human capital is equal to the potential subject specific human capital:

$$
g p a_{f}=\eta_{0}^{f}+\eta_{1}^{v, f} H_{1}^{v}+\eta_{2}^{m, f} H_{1}^{m}+\eta_{3}^{f}\left(H_{1}^{f} \times\left(f=f^{*}\right)+H_{0}^{f} \times\left(f \neq f^{*}\right)\right)+u_{f}^{g p a}
$$

The GPA measurements are assumed to be missing at random, and the random components $u_{f}$ are assumed to be mean zero, independent of each other but can have different distributions. Similarly to our interpretation of the SAT measures, we view these components as scholastic abilities orthogonal to the human capital.

\subsubsection{The individuals' information set}

We specify the rest of the model under two possible information sets for individuals. In the first case we assume that individuals observe directly their pre-college general human capital and their potential specific human capital for all fields. Alternatively we assume that the students cannot directly observe these measures while in college but only some noisy measures. These noisy measures are assumed to be the SATs that are also observed by the econometrician and a set of "potential" GPAs defined for all fields as follow:

$$
g p a_{f}^{P}=\eta_{0}^{f}+\eta_{1}^{v, f} H_{0}^{v}+\eta_{2}^{m, f} H_{0}^{m}+\eta_{3}^{f} H_{0}^{f}+u_{f}^{g p a}
$$

Notice that the potential GPA does not depend on the field that is eventually chosen and are unobserved to the econometrician. We do assume, however, that the idiosyncratic component $u_{f}^{g p a}$ is the same as the idiosyncratic component of the observed GPAs. Once in the labor market we assume that individuals are able to perfectly observe their human capital.

\subsection{The Dynamic Problem}

Upon entering the labor market, individuals must decide whether to obtain a graduate degree, which occupation to work in, and whether to work in a job related to their field of study. At this stage we assume that these choices are driven by probabilities that are functions of the human capitals $H_{1}=\left(H_{1}^{g}, H_{1}^{f^{*}}\right)$ and the major chosen $f^{*}$.

The probability of having a graduate degree is one if a degree has already been acquired in the past and $P_{G, t}\left(f^{*}, H_{1}, Z_{G, t}\right)$ otherwise. The probability of selecting occupation $o$ is given by $P_{o, t}\left(f^{*}, H_{1}, Z_{o, t}, G_{t}\right)$, while the probability of working in a related job is 
$P_{r, t}\left(f^{*}, H_{1}, Z_{r, t}, G_{t}, o_{t}\right)$. The variables $\left(Z_{G, t}, Z_{o, t}, Z_{r, t}\right)$ are exogenous shifters. In the empirical implementation we use the state variation from the national average of the share of workers in each category.

We assume that the value of retirement is equal to the present discounted value of the utility derived from the pension payments, which are assumed to be equal to the last wage earned in the market. While working, the value function at the beginning of a period $t$ is given by:

$$
V_{t}\left(H_{t}, G_{t-1}, f^{*}, Z\right)=E_{g, o, r}\left\{\frac{1-\beta^{T_{t}}}{1-\beta} U(w(\cdot))+\beta^{T_{t}} V_{t+1}(\cdot)\right\},
$$

where $T_{t}$ indicates the number of years contained in each period and $U\left(w_{t}\right)=\frac{w_{t}^{\sigma}-1}{\sigma}$. The value function prior to the major choice while in college is given by:

$$
V_{0}\left(H_{0}, Z, S A T, g p a^{P}\right)=E \max _{f}\left\{C_{f}(\cdot)+\delta V_{1}(\cdot)\right\}
$$

in the case of perfect knowledge or:

$$
V_{0}\left(Z, S A T, g p a^{P}\right)=E \max _{f}\left\{C_{f}(\cdot)+\delta E_{u} V_{1}(\cdot)\right\}
$$

in the case of imperfect information. The non-monetary component $C_{f}$, which is specified below, captures not only the difference in the preferences for studying each field but also captures the fact that individuals might have non-monetary benefits associated with the expected future career profiles that originate from each major choice. We assume that this component, rather than being directly a function of the human capitals or their expectations is a direct function of the SAT measures and the unobserved potential GPAs. This is consistent with our interpretation of the random component $u$ as scholastic ability:

$$
C_{f}^{U G}(\cdot)=c_{f}^{U G, c}+c_{f}^{U G, m} S A T^{m}+c_{f}^{U G, v} S A T^{v}+c_{f}^{U G, s} G P A_{f}^{P}+C_{f}^{U G, z} Z_{f}+\varepsilon_{f}^{U G},
$$

where the random component is assumed to be drawn from a standard extreme value distribution. Notice that in the case of imperfect information, the assumption that the SATs and the potential GPAs rather than the expected human capitals enter in the non-monetary component of the utility is without loss of generality, given that the expected human capitals are functions of the noisy measures observed by the student, which are indeed the SATs and the potential GPAs. The vector of variables $Z_{f}$ are assumed to be exogenous conditional on observables. In our empirical implementation we use the state specific share of students in 
each major and the share of students in each field at the college chosen. While we can imagine that the college is not chosen randomly, we assume that conditional on the SATs this variable may still be correlated to the choice but not through the human capitals.

\subsection{Implementation}

Using an identification strategy similar to Carneiro et al. (2003), we can show that the above model is identified with some normalizations. However, estimation is significantly simpler if we rewrite some of the parameters in a slightly more general specification that nests our original model. More specifically, the simplifications proposed in this section will allow us to treat the initial human capitals as uncorrelated factors that do not change over time when estimating the model.

Define the following variables $\tilde{H}_{0}^{m}=H_{0}^{m}-\mu^{m}$ and $\tilde{H}_{0}^{f^{*}}=H_{0}^{f^{*}}-\mu^{f^{*}}$, and the linear projection:

$$
H_{0}^{v}=\mu^{v}+\sigma / \sigma_{H_{0}^{m}}^{2} \tilde{H}_{0}^{m}+\sqrt{\left(1-\sigma^{2}\right) / \sigma_{H_{0}^{m}}^{4}} \tilde{H}_{0}^{v}
$$

where $\sigma$ is the covariance between the general human capitals and $\sigma_{H_{0}^{m}}^{2}$ is the variance of the initial math human capital. Substituting the post-schooling human capitals with their definitions in terms of college major and initial human capitals (and omitting the graduate degree dummy, the year dummy and the exogenous vector for simplicity) and the initial human capitals with the newly defined factors we can write the wage equation as:

$$
\ln w_{t}=\lambda_{o r}^{f^{*}}+\lambda_{o}^{m, f^{*}} \widetilde{H}_{0}^{m}+\lambda_{o}^{v, f^{*}} \widetilde{H}_{0}^{v}+\lambda_{o}^{f^{*}} \tilde{H}_{0}^{f^{*}} \times 1\left(r_{t}=1\right)
$$

where now the coefficients that multiply the initial human capitals are major and occupation specific, the constant is major/occupation/relationship specific and all human capital factors are uncorrelated among each other. Using the same strategy we can also write:

$$
g p a_{f}=\eta_{0}^{f, f^{*}}+\eta_{1}^{v, f, f^{*}} \widetilde{H}_{0}^{v}+\eta_{2}^{m, f, f^{*}} \tilde{H}_{0}^{m}+\eta_{3}^{f} \widetilde{H}_{0}^{f}+u_{f}^{g p a} .
$$

Although we do not directly estimate the coefficients $\rho^{j, f^{*}}$, it is clear that we need to normalize the coefficients for one of the majors since our sample contains only college graduates. The potential GPAs will be then defined as the GPA measures that a student would obtain had he chosen to graduate in this benchmark major, which in our empirical implementation is the residual major. 
Further, define $u_{v}=\alpha / \sigma_{u_{m}}^{2} u_{m}+\tilde{u}_{v}$ where $\alpha$ is the covariance between the non-human capital random components of the SATs and $\sigma_{u_{m}}^{2}$ is the variance of the math residual component. We can write the verbal SAT measurement as:

$$
S A T_{v}=\tilde{\eta}_{c}^{v}+\eta^{v} \frac{\sigma}{\sigma_{H_{0}^{m}}^{2}} \widetilde{H}_{0}^{m}+\eta^{v} \frac{\alpha}{\sigma_{u_{m}}^{2}} u_{m}+\tilde{\eta}^{v} \widetilde{H}_{0}^{v}+\tilde{\tilde{u}}_{v}
$$

Although we can show identification for our model under the assumption that $u_{m}$ and $u_{v}$ are uncorrelated, our initial attempts to estimate such a model convinced us that this is not a reasonable assumption. The SAT math and verbal are taken at the same time and someone who performs well on the math test is also likely to perform well on the verbal test, independent of the true underlying abilities. Unfortunately, given the available data and our model we cannot allow $\alpha$ to be a free parameter. Looking at the previous equation, we found it reasonable and convenient to assume that the correlation between the math and verbal abilities is similar to the correlation between the residual random components. Specifically, we assume that:

$$
\frac{\operatorname{cov}\left(\widetilde{H}_{0}^{m}, \widetilde{H}_{0}^{v}\right)}{\operatorname{var}\left(\widetilde{H}_{0}^{m}\right)}=\frac{\operatorname{cov}\left(u_{m}, u_{v}\right)}{\operatorname{var}\left(u_{m}\right)},
$$

which means that the projection coefficient of the math ability onto the verbal ability is equal to the projection coefficient of the math residual component onto the verbal residual component. Under this assumption the coefficients multiplying the two math specific random components in the SAT verbal test are equal to each other, which implies that the verbal SAT test can be written as a linear function of the math SAT, the newly defined uncorrelated verbal human capital and the orthogonal verbal component $\tilde{\tilde{u}}_{v}$. Under this assumption the residual SAT verbal measurement simplifies to:

$$
S A T_{v}^{R}=\tilde{\eta}^{v} \widetilde{H}_{0}^{v}+\tilde{\tilde{u}}_{v}
$$

The interesting feature of this assumption is that it allow us to have a correlation in the error term and furthermore use the SAT math test and use the residual SAT verbal test as "dedicated" measures of the math and verbal initial human capital, which is a useful feature for the identification of the model. 


\subsection{Identification}

In this section we provide an intuitive explanation for the identification of some of the most important parameters of the model. We focus this discussion exclusively on the identification of the wage and measurement parameters. ${ }^{14}$ Our strategy is based on an infinity argument as in Carneiro et al. (2003). This assumptions implies that we can move some element of the vector of exogenous variables $Z$ in such a way that the resulting probability of selecting a certain combination of major choice, job choice, graduate school outcome is equal to one. Clearly the infinity argument is a strong argument when compared to the patterns that we observe in the data. Our point of view is that this identification strategy gives us an idea that the data can be theoretically rich enough to identify the model even without using restrictions implied by distributional assumptions, although those assumptions will help in the actual implementation of the estimation.

For the sake of simplifying the discussion, assume that agents cannot go to graduate school. In our empirical implementation we assume that agents can choose among 3 majors and 3 occupations. As we mentioned in the model section, we need to normalize some parameters. We choose to normalize all variances of the initial human capitals, $\left(\widetilde{H}_{0}^{m}, \widetilde{H}_{0}^{v}, \widetilde{H}_{0}^{0}, \widetilde{H}_{0}^{1}, \widetilde{H}_{0}^{2}\right)$, to one. This is done without loss of generality. We also assume that the loading factor of the math human capital for the math SAT, the loading factor of the verbal human capital for the verbal SAT and the loading factors of the specific human capitals in the GPAs are positive, again without loss of generality.

We start by considering the identification of the parameters relative to the general human capitals: the loading factors in the wage and the loading factors in the measurement equations. Leaving aside the constant terms, the corresponding parameters are given by $\left(\lambda_{o}^{m, f^{*}}, \lambda_{o}^{v, f^{*}}, \eta_{1}^{m}, \eta_{1}^{v}\right)$.

Consider first the set of agents that have probability one of choosing major $f$ and occupation $o$ or $o^{\prime}$ and not working in a related job. We can construct six covariances using the auto-covariances of wages for the two occupations and the covariances of the wages in the two

\footnotetext{
${ }^{14}$ One key assumption for the identification of the parameter $\delta$ that distinguishes the monetary from the non monetary factors for the major choice of the individual is the presence of a variable that affects the labor market outcomes but does not enter in the non-monetary component of the utility. For example the variables in $Z_{w}$ satisfy such requirement.
} 
occupations with the two SAT measures.

$$
\begin{aligned}
A & =\operatorname{cov}\left(\ln w_{o t}, \ln w_{o t-1}\right)=\left(\lambda_{o}^{m, f^{*}}\right)^{2}+\left(\lambda_{o}^{v, f^{*}}\right)^{2} \\
B & =\operatorname{cov}\left(\ln w_{o t}, S A T_{m}\right)=\lambda_{o}^{m, f^{*}} \eta^{m} \\
C & =\operatorname{cov}\left(\ln w_{o t}, S A T_{v}^{R}\right)=\lambda_{o}^{v, f^{*}} \tilde{\eta}^{v} \\
A^{\prime} & =\operatorname{cov}\left(\ln w_{o^{\prime}}, \ln w_{o^{\prime} t-1}\right)=\left(\lambda_{o^{\prime}}^{m, f^{*}}\right)^{2}+\left(\lambda_{o^{\prime}}^{v, f^{*}}\right)^{2} \\
B^{\prime} & =\operatorname{cov}\left(\ln w_{o^{\prime}}, S A T_{m}\right)=\lambda_{o^{\prime}}^{m, f^{*}} \eta^{m} \\
C^{\prime} & =\operatorname{cov}\left(\ln w_{o^{\prime} t}, S A T_{v}^{R}\right)=\lambda_{o^{\prime}}^{v, f^{*}} \tilde{\eta}^{v}
\end{aligned}
$$

Manipulating these six equations (with six unknowns) we can obtain a solution for $\left(\eta^{m}\right)^{2}$ :

$$
\left(\eta^{m}\right)^{2}=\frac{B^{\prime 2} C^{2}-B^{2} C^{\prime 2}}{A^{\prime} C^{2}-C^{\prime 2} A}
$$

Given our normalization on the sign of $\eta^{m}$, as long as the denominator is not equal to zero, we have identification of the parameter and the identification of the remaning five parameters easily follows.

Identification of the remaining parameters related to the general human capitals is simple to obtain using a similar strategy. The average wage for a particular occupation/major group in a non related job identifies the wage constant for that group. The constants in the SAT measurement equations are identified using the average SAT scores.

Consider now individuals who work in a related job and in a particular occupation with probability one. The auto-covariance of wages for these workers identifies the loading of the specific human capital in the wage. Again, the wage constants can simply be identified by looking at the average value of these wages.

The parameters of the GPA measurement equations remain to be identified. The covariances of SATs with all GPAs for different choices of majors identifies the loadings on the general human capitals in the GPA measurements. Looking at the covariances between wages in related jobs and the subject specific GPA of the chosen major identifies the loading factors of the subject specific human capital in the measurement equations. Finally the constant terms in the GPA measures can be identified looking at the average GPAs by major chosen. The variances of the measurements (SATs and GPAs) finally identifies the variances of the noise, or "scholastic" ability. A more detailed discussion on the identification of the structural parameters is available upon request. 


\section{Estimation and Results}

In this section we discuss estimation of the model parameters. Two parameters that we do not estimate are the coefficient of risk aversion and the discount factor. We estimate the model using standard log-utility but also using a coefficient of risk aversion equal to 2 as in Gourinchas and Parker (2002). The yearly discount factor is set equal to 0.95 also following Gourinchas and Parker (2002). We estimate our model by maximum likelihood. In this version of the paper we simplify further our framework and assume that the return to major choice does not depend on the level of initial human capital. This implies that in this set-up selection is completely driven by the non-monetary component of utility. Let the data for an individual $i$ be:

$$
Y_{i}=\left\{M_{i}, S A T_{i}, G P A_{i}, G R A D_{i, t}, R E L_{i, t}, O C C_{i, t}, w_{i, t}, Z_{i}\right\} \quad \text { for } t \in\{1994,1997,2003\}
$$

where $M_{i}=\{$ Science $(\mathrm{S})$, Business $(\mathrm{B}), \operatorname{Other}(\mathrm{O})\}, R E L_{i t}=\{$ Related, Non-Related $\}, O C C_{i t}=$ \{Blue, Pink, White\}, $S A T_{i}$ includes both math and residual verbal scores, and $G P A_{i}$ includes grades across the three major fields. $Z$ is the vector of exclusion restrictions. $\Omega$ is the vector of parameters that describe the model.

\subsection{No Human Capital Uncertainty}

We first present the estimation strategy and results for the case where individuals have no uncertainty regarding their underlying human capital. Suppose for a moment that the vector of human capitals, $H_{i}=\left\{H_{i, 0}^{m}, H_{i, 0}^{v}, H_{i, 0}^{S}, H_{i, 0}^{B}, H_{i, 0}^{O}\right\}$ and the vector of the uniquenesses of the measurement equations $u_{i}=\left\{u_{m, i}, u_{v, i}, u_{S, i}, u_{B, i}, u_{O, i}\right\}$ are known to the econometrician. Under this assumption, the individual contribution to the likelihood function $L\left(Y_{i} \mid Z_{i}, H_{i}, u_{i} ; \Omega\right)$ 
can be written as follows:

$$
\begin{aligned}
L(Y \mid Z, H, u ; \Omega)= & \operatorname{Pr}(M \mid Z, H, u ; \Omega) \\
& \times \prod_{j \in\{m, v\}} 1\left(S A T_{j}=s a t_{j}(H, u ; \Omega)\right) \times \prod_{j \in\{S, B, O\}} 1\left(G P A_{j}=g p a_{j}(M, H, u ; \Omega)\right) \\
& \times \prod_{t \in\{1994,1997,2003\}} \operatorname{Pr}\left(G R A D_{t} \mid Z, H, M, G R A D_{t-1} ; \Omega\right) \\
& \times \prod_{t \in\{1994,1997,2003\}} \operatorname{Pr}\left(O C C_{t} \mid Z, H, M, G R A D_{t} ; \Omega\right) \\
& \times \prod_{t \in\{1994,1997,2003\}} \operatorname{Pr}\left(R E L_{t} \mid Z, H, M, G R A D_{t}, O C C_{t} ; \Omega\right) \\
& \times \prod_{t \in\{1994,1997,2003\}} f_{u_{t}^{\text {wage }}\left(w_{t} \mid Z, H, M, G R A D_{t}, O C C_{t}, R E L_{t} ; \Omega\right)}
\end{aligned}
$$

where for ease of presentation we suppress the individual subscripts. In order to calculate the terms in the above likelihood function we need to impose some parametric assumptions. As noted earlier, we assume that the utility for each major choice contains an idiosyncratic extreme-value shock, which yields a simple logit-type probability for major choice. Similarly, we assume that the probability of obtaining a graduate degree, working in a particular occupation, and working in a related job take a simple logit form. Finally, we assume that the measurement error in the wages is normally distributed.

Of course the econometrician cannot observe $H_{i}$ or $u_{i}$, so we cannot evaluate the above likelihood function directly. The unobserved human capitals must be integrated out of the likelihood function:

$$
L(Y \mid Z ; \Omega)=\int L(Y \mid Z, H, u ; \Omega) d F_{H, u}(H, u ; \Omega)
$$

We assume that the unobserved human capitals and the uniquenesses of the measurement equations are normally distributed, and take 1,000 draws from the vector of the unobserved human capitals in order to evaluate the above integral.

The full set of 162 parameter estimates from the model with no uncertainty and log-utility is available upon request. We postpone interpretation until the next section where we use the model to estimate the returns to college major and decompose the variance of wages into its various components. However, to provide some confidence in the ability of the model to match the data, we do a simple validation exercise. Using the estimated model parameters we 
simulate major choices and labor market outcomes for a large number individuals (10 times the size of the original sample). We then compare the simulated data to the actual data, the results of which are shown in Tables 7 and 8. In Table 7 we can see that our model does a decent job fitting the basic patterns in the data and reproduces remarkably well the sorting across majors. Table 8 indicates that our model is able to capture the key patterns from our reduced-form wage regressions although some differences remain. In the simulated data, working in a related job significantly boosts earnings. The magnitude of the estimated effect is quite similar across the simulated and actual data although it is slightly overestimated for business and underestimated for science. The magnitude of the coefficients for the measures of observed abilities is consistent between the two samples but we slightly overestimate the impact of math SAT and underestimate the impact of GPA.

\subsection{Human Capital Uncertainty}

In this section we allow for the possibility that individuals are uncertain about their true labor market productivities. We assume that at the time the schooling decisions are made, each individual knows their SAT and potential GPA measures, but not the true underlying human capitals. Allowing for human capital uncertainty alters the likelihood function and estimation procedure in the following fashion. First, the probability of choosing a particular major is now a function of the $S A T$ and potential GPA measures. Notice that the potential $G P A$ is not observable to the econometrician so we still need to utilize the integrated approach seen above. Thus, we replace $\operatorname{Pr}(M \mid Z, H, u ; \Omega)$ in $L(Y \mid H, Z ; \Omega)$ with:

$$
\operatorname{Pr}\left(M \mid Z, S A T(H, u), G P A^{P}(H, u) ; \Omega\right)
$$

The probability of making a particular major choice is a function of the future expected labor market returns. In order to determine what the expected labor market returns are for each major in the case of uncertainty, individuals must integrate over the distribution of the true human capitals given the $S A T$ and potential GPA measures available to them. Using the notation from the recursive formulation of of the individual's choice problem, this integral takes the following form:

$$
E V_{1}(\cdot \mid f)=\int V_{1}(H, 0, f, Z) d F_{H}\left(H \mid S A T, G P A^{P}, f ; \Omega\right)
$$


To calculate this integral, we utilize the labor market returns for each of the 1,000 draws of the underlying human capitals that we already calculated for each individual. We then weight these returns according to their likelihood of occurring given the $S A T$ and potential GPA measures. The weights are straightforward to calculate since conditional on a set of parameters and "true" human capitals, we can easily determine the joint probability of the implied uniqueness in the $S A T$ and potential GPA measures.

We are still in the process of estimating this version of the model with log-utility. The extra integration for the calculation of the expected value function increases considerably the computational time. We report in table 9 and 10 the fit obtained using the partial estimates although it is clear that the fit will improve. As it is evident from table 10 we are severely underestimating the returns to business and science related majors, although the relationship related coefficients look even better than in the previous model.

\section{Counterfactuals}

In this section we perform a set of simple counterfactual experiments. We simulate major choices and labor market outcomes for a large number of individuals (10 times the size of the original sample) utilizing our estimated model. A key benefit of our structural approach is that we are able to simulate labor market outcomes for all majors, not just the chosen one.

\subsection{The Returns to Major Choice}

Here we provide our estimates of the average return to each major if we forced students into a certain major (Average Treatment Effect - ATE), the average return to each major for those who selected that major (Treatment of the Treated - TT), and finally the average return for those that selected a different major (Treatment of the Untreated - TUT). In table 11, we report the results for the model with perfect knowledge, jointly with the OLS estimates from table 8 , which are included in the first column. In the second column we report the ATE. The average returns are clearly positive but also much smaller than the returns estimated by OLS. This suggests that although the average student would have higher wages with a business or science degree, the returns are not very large.

In the remaining columns we report the average returns for those who selected a business, 
science, or residual major, respectively. Note that the the return for those who selected a certain major (TT) are much larger than the ATE. For example, we see that the return to choosing science versus the residual category is on average 0.08 but it is 0.15 for those that actually chose science. Although the difference between the ATE and the TT can be driven by both the general human capital (through the different prices) and the specific human capital, it turns out to be mainly driven by the latter. The same is true for the return to business where the difference between ATE and TT is even stronger. Notice that the students who selected business or science have selected the most profitable major. Although the students that selected the residual category could have done better choosing science, the extra return would have been quite modest. Analyzing the differences between the TT and the OLS estimates we can conclude that just looking at the correlations between log wages and major in the data overestimates the true returns to major choice.

In table 12 we report the same estimates relative to the model with imperfect knowledge, although the estimation is not complete. Interestingly once we remove the assumption that individuals know their labor market abilities, there is a much smaller difference between the ATE and TT. Although the differences are small, the TT move in the expected direction with respect to the ATE.

\subsection{The Importance of General vs. Specific HC}

In table 13 we decompose wages into elements related to general and specific human capital. We report the average value and the dispersion (in standard deviations) of the overall wage and each component for all majors in the case of perfect knowledge. The wage components not included in the table are those related to the year and graduate studies effects, and those related to the exogenous controls and measurement error. Consistent with our reduced form analysis, we see that the average value of the specific component is much larger for the science majors. In fact, it is large and positive only for this group while the magnitude is quite small in the other two groups. The two types of human capital, general and major specific, account for a large fraction of the dispersion in wages, indicating that the model is indeed able to capture the patterns of the data also in terms of distributions. The specific human capital itself is characterized by a large standard deviation (non-related jobs are included with zero specific human capital). Interestingly, the standard deviation of the specific human capital is 
much smaller for the residual major. Although the specific human capital has basically the same dispersion across business and science majors, it accounts for a larger share of the total dispersion for science majors.

In table 14 we report the statistics relative to the model with imperfect knowledge, although the estimation is not complete. In this model, we see that the dispersion in wages due to specific human capital is generally higher, in particular for the science graduates.

\subsection{The Role of Imperfect Information}

We perform a final exercise related to the students information set at the time of the major choice. We take the estimates from the model assuming perfect information over the human capital endowments and we feed them into the model that assumes students have imperfect information. The fraction of students choosing the residual major increases from $48 \%$ to $74 \%$. The fraction of business majors decreases from $26 \%$ to $11 \%$ and the fraction of science related majors also decreases from $26 \%$ to $14 \%$. Similarly, when we feed the estimates from the model that assumes imperfect information to the model that assumes perfect information we see that the fraction of students in the residual major goes down from $45 \%$ to $40 \%$, while business and science graduates increase from $29 \%$ and $26 \%$ to $32 \%$ and $28 \%$ respectively. These results

indicate that if students are not perfectly aware of their labor market abilities, they tend to choose the safer residual majors more frequently.

\section{Conclusion}

TBA 


\section{References}

Altonji, Joseph G., "The Demand for and Return to Education When Education Outcomes are Uncertain," Journal of Labor Economics, 1993, 11 (1), pp. 48-83.

Arcidiacono, Peter, "Ability sorting and the returns to college major," Journal of Econometrics, 2004, 121 (1-2), 343-375.

Becker, Gary S., "Investment in Human Capital: A Theoretical Analysis," Journal of Political Economy, 1962, 70 (5), pp. 9-49.

Beffy, Magali, Denis Fougre, and Arnaud Maurel, "Choosing the Field of Study in Post-Secondary Education: Do Expected Earnings Matter?," Forthcoming in Review of Economics and Statistics, 2009, (4127).

Carneiro, Pedro, Karsten T. Hansen, and James J. Heckman, "2001 Lawrence R. Klein Lecture Estimating Distributions of Treatment Effects with an Application to the Returns to Schooling and Measurement of the Effects of Uncertainty on College Choice," International Economic Review, 05 2003, 44 (2), 361-422.

Gathmann, Christina and Uta Schnberg, "How General Is Human Capital? A TaskBased Approach," Journal of Labor Economics, 2010, 28 (1), 1-49.

Gourinchas, Pierre-Olivier and Jonathan A. Parker, "Consumption Over the Life Cycle," Econometrica, 2002, 70 (1), 47-89.

Keane, Michael P and Kenneth I Wolpin, "The Career Decisions of Young Men," Journal of Political Economy, 1997, 105 (3), 473-522.

Kennan, John and James R. Walker, "The Effect of Expected Income on Individual Migration Decisions," Econometrica, 2011, 79 (1), 211-251.

Lee, Donghoon and Kenneth I. Wolpin, "Intersectoral Labor Mobility and the Growth of the Service Sector," Econometrica, 01 2006, 74 (1), 1-46.

McCall, Brian P., "Occupational Matching: A Test of Sorts," Journal of Political Economy, 1990, 98 (1), pp. 45-69. 
Mincer, Jabob, "Investment in Human Capital and Personal Income Distribution," Journal of Political Economy, 1958, 66 (4), 281-302.

Montmarquette, Claude, Kathy Cannings, and Sophie Mahseredjian, "How do young people choose college majors?," Economics of Education Review, 2002, 21 (6), 543556.

Murphy, Kevin M., Andrei Shleifer, and Robert W. Vishny, "The Allocation of Talent: Implications for Growth," The Quarterly Journal of Economics, 1991, 106 (2), pp. $503-530$.

Neal, Derek, "Industry-Specific Human Capital: Evidence from Displaced Workers," Journal of Labor Economics, 1995, 13 (4), pp. 653-677.

Nielsen, Helena Skyt and Annette Vissing-Jorgensen, "The Impact of Labor Income Risk on Educational Choices: Estimates and Implied Risk Aversion," 2010. Working Paper.

Oi, Walter Y., "Labor as a Quasi-Fixed Factor," Journal of Political Economy, 1962, 70 (6), pp. 538-555.

Parent, Daniel, "Industry?Specific Capital and the Wage Profile: Evidence from the National Longitudinal Survey of Youth and the Panel Study of Income Dynamics," Journal of Labor Economics, 2000, 18 (2), pp. 306-323.

Pavan, Ronni, "Career Choice and Wage Growth," Journal of Labor Economics, 2011, 29 (3), pp. 549-587.

Poletaev, Maxim and Chris Robinson, "Human Capital Specificity: Evidence from the Dictionary of Occupational Titles and Displaced Worker Surveys, 1984-2000," Journal of Labor Economics, 2008, 26 (3), 387-420.

Sullivan, Paul, "A Dynamic Analysis Of Educational Attainment, Occupational Choices, And Job Search," International Economic Review, 2010, 51 (1), 289-317.

Yamaguchi, Shintaro, "Tasks and Heterogeneous Human Capital," Forthcoming in Journal of Labor Economics, September 2011, (2011-06). 
Table 1: Schooling Statistics

\begin{tabular}{|c|c|c|c|c|c|}
\hline \multicolumn{2}{|l|}{ Overall } & \multicolumn{4}{|c|}{ by Major } \\
\hline & & & Business & Science & Other \\
\hline \multirow[t]{2}{*}{ Age in 1993} & 23.31 & SAT Math & 525 & 596 & 525 \\
\hline & $(1.48)$ & & $(113)$ & $(106)$ & $(111)$ \\
\hline \multirow[t]{2}{*}{ SAT Math } & 542 & SAT Verbal & 450 & 496 & 474 \\
\hline & $(116)$ & & $(98)$ & $(105)$ & $(102)$ \\
\hline \multirow[t]{3}{*}{ SAT Verbal } & 473 & Business GPA & 3.14 & 3.07 & 2.71 \\
\hline & $(103)$ & & $(0.44)$ & $(0.75)$ & $(0.78)$ \\
\hline & & Business Credits & 37.04 & 2.91 & 5.70 \\
\hline \% Business Major & 26.12 & & $(18.98)$ & $(7.55)$ & $(12.16)$ \\
\hline \multirow[t]{2}{*}{ \% Math/Science Major } & 24.66 & Science GPA & 2.75 & 3.23 & 2.62 \\
\hline & & & $(0.65)$ & $(0.47)$ & $(0.7)$ \\
\hline \multirow[t]{2}{*}{ \% Other Major } & 49.22 & Science Credits & 20.01 & 78.43 & 17.93 \\
\hline & & & $(12.61)$ & $(29.34)$ & $(17.24)$ \\
\hline \multirow[t]{2}{*}{ \% Graduate Degree } & 27.34 & & & & \\
\hline & & Other GPA & 2.89 & 3.14 & 3.23 \\
\hline \multirow[t]{3}{*}{ Log(Parental Income) } & 10.91 & & $(0.51)$ & $(0.53)$ & $(0.45)$ \\
\hline & $(0.7)$ & Other Credits & 43.00 & 29.34 & 62.69 \\
\hline & & & $(25.51)$ & $(19.88)$ & $(33.47)$ \\
\hline \multirow[t]{3}{*}{ Avg. Parental Yrs. Of Schooling } & 14.85 & & & & \\
\hline & $(2.22)$ & Log(Parental Income) & 10.92 & 10.84 & 10.95 \\
\hline & & & $(0.73)$ & $(0.7)$ & $(0.68)$ \\
\hline \multirow[t]{4}{*}{ Both Parents Foreign Born } & 0.08 & & & & \\
\hline & & Parental Schooling (Yrs.) & 14.67 & 14.84 & 14.95 \\
\hline & & & $(2.13)$ & $(2.32)$ & $(2.21)$ \\
\hline & & Both Parents Foreign Born & 0.08 & 0.13 & 0.04 \\
\hline
\end{tabular}


Table 2: Labor Market Statistics

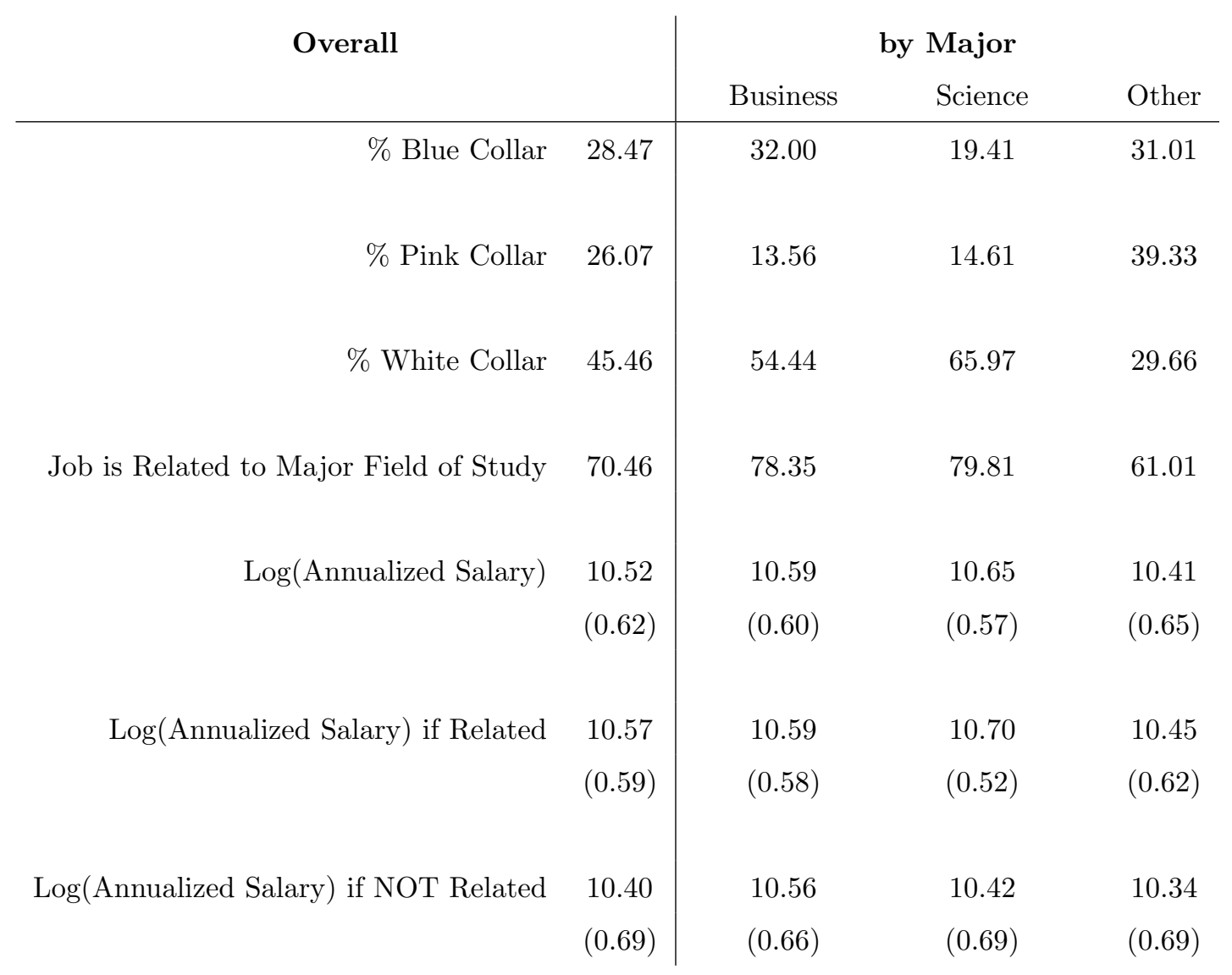


Table 3: Returns to College Major

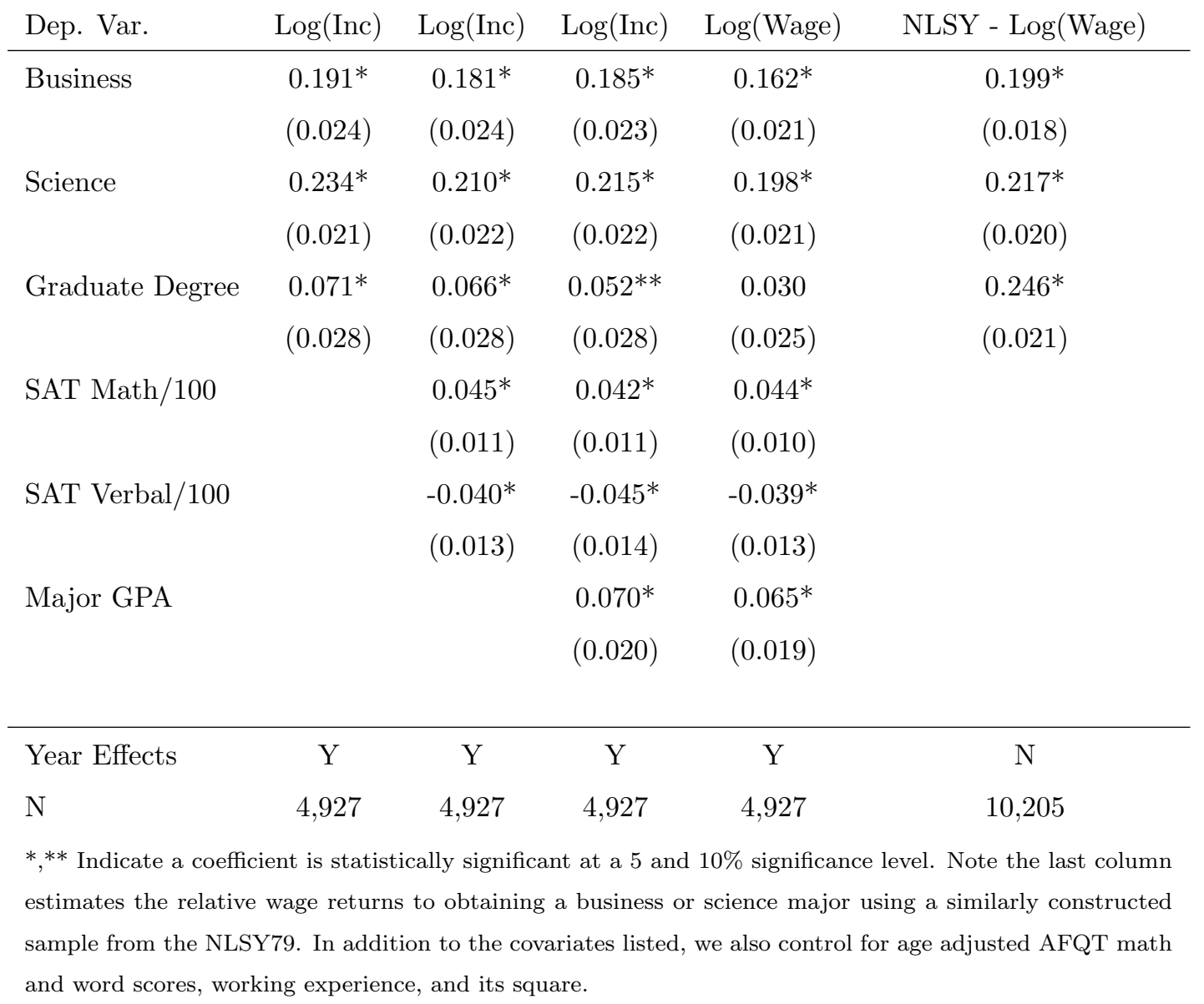


Table 4: Returns to College Major Accounting for Occupation

\begin{tabular}{lccc} 
Dep. Var. & $\log ($ Income $)$ & $\log ($ Income $)$ & $\log ($ Income $)$ \\
\hline Business & $0.185^{*}$ & $0.093^{*}$ & $0.071^{*}$ \\
& $(0.023)$ & $(0.022)$ & $(0.022)$ \\
Science & $0.215^{*}$ & $0.107^{*}$ & $0.115^{*}$ \\
& $(0.022)$ & $(0.022)$ & $(0.024)$ \\
Graduate Degree & $0.052^{* *}$ & $0.067^{*}$ & $0.050^{* *}$ \\
SAT Math/100 & $(0.028)$ & $(0.028)$ & $(0.028)$ \\
& $0.042^{*}$ & $0.028^{*}$ & $0.021^{*}$ \\
SAT Verbal/100 & $(0.011)$ & $(0.010)$ & $(0.010)$ \\
& $-0.045^{*}$ & $-0.037^{*}$ & $-0.041^{*}$ \\
Major GPA & $(0.014)$ & $(0.013)$ & $(0.013)$ \\
& $0.070^{*}$ & $0.076^{*}$ & $0.078^{*}$ \\
Pink Collar & $(0.020)$ & $(0.019)$ & $(0.018)$ \\
& & $-0.223^{*}$ & \\
White Collar & & $(0.028)$ & \\
Year Effects & & $0.161^{*}$ & $\mathrm{Y}$ \\
Detailed Occupation Effects & $\mathrm{N}$ & $(0.020)$ & $\mathrm{Y}$ \\
N & 4,927 & 4,927 & $\mathrm{Y}$ \\
\hline Indicate a coefficient is statistically significant at a 5 and $10 \%$ significance level.
\end{tabular}


Table 5: Returns to College Major Accounting for Utilization

\begin{tabular}{|c|c|c|c|c|c|}
\hline Dep. Var. & $\log (\operatorname{Inc})$ & $\log (\operatorname{Inc})$ & $\log (\operatorname{Inc})$ & $\log (\operatorname{Inc})$ & $\log (\operatorname{Inc})$ \\
\hline \multirow[t]{2}{*}{ Business } & $0.143^{*}$ & & & $0.113^{*}$ & \\
\hline & $(0.051)$ & & & $(0.048)$ & \\
\hline \multirow[t]{2}{*}{ Science } & 0.019 & & & 0.000 & \\
\hline & $(0.047)$ & & & $(0.045)$ & \\
\hline \multirow[t]{2}{*}{ Job is Related to Studies } & $0.063^{* *}$ & 0.019 & 0.048 & $0.100^{*}$ & $0.061^{* *}$ \\
\hline & $(0.035)$ & $(0.030)$ & $(0.030)$ & $(0.034)$ & $(0.030)$ \\
\hline \multirow[t]{2}{*}{ Business*Job is Related to Studies } & 0.039 & $0.096^{* *}$ & 0.003 & -0.046 & -0.027 \\
\hline & $(0.058)$ & $(0.055)$ & $(0.048)$ & $(0.056)$ & $(0.047)$ \\
\hline \multirow[t]{2}{*}{ Science* Job is Related to Studies } & $0.229^{*}$ & $0.227^{*}$ & $0.118^{*}$ & $0.114^{*}$ & 0.079 \\
\hline & $(0.051)$ & $(0.049)$ & $(0.054)$ & $(0.052)$ & $(0.053)$ \\
\hline \multirow[t]{2}{*}{ Graduate Degree } & 0.030 & 0.044 & $0.189^{*}$ & $0.048^{* *}$ & $0.179 *$ \\
\hline & $(0.028)$ & $(0.029)$ & $(0.030)$ & $(0.027)$ & $(0.029)$ \\
\hline \multirow[t]{2}{*}{ SAT Math/100 } & $0.041^{*}$ & $0.031^{*}$ & & $0.028^{*}$ & \\
\hline & $(0.011)$ & $(0.011)$ & & $(0.010)$ & \\
\hline \multirow[t]{2}{*}{ SAT Verbal/100 } & $-0.042^{*}$ & $-0.033^{*}$ & & $-0.033^{*}$ & \\
\hline & $(0.013)$ & $(0.012)$ & & $(0.012)$ & \\
\hline \multirow[t]{2}{*}{ Major GPA } & $0.064^{*}$ & $0.085^{*}$ & & $0.070^{*}$ & \\
\hline & $(0.020)$ & $(0.019)$ & & $(0.019)$ & \\
\hline Year Effects & $\mathrm{Y}$ & $\mathrm{Y}$ & $\mathrm{Y}$ & $\mathrm{Y}$ & $\mathrm{Y}$ \\
\hline Worker Fixed Effects & $\mathrm{N}$ & $\mathrm{N}$ & $\mathrm{Y}$ & $\mathrm{N}$ & $\mathrm{Y}$ \\
\hline Detailed Major Effects & $\mathrm{N}$ & $\mathrm{Y}$ & $\mathrm{N}$ & $\mathrm{N}$ & $\mathrm{N}$ \\
\hline Occupation Effects & $\mathrm{N}$ & $\mathrm{N}$ & $\mathrm{N}$ & $\mathrm{Y}$ & $\mathrm{Y}$ \\
\hline $\mathrm{N}$ & 4,927 & 4,927 & 4,927 & 4,927 & 4,927 \\
\hline
\end{tabular}


Table 6: Returns to Working in a Related Job

\begin{tabular}{|c|c|c|c|c|c|c|}
\hline Dep. Var. & $\log (\operatorname{Inc})$ & $\log (\operatorname{Inc})$ & $\log (\operatorname{Inc})$ & & $\Delta \log (\operatorname{Inc})$ & $\Delta \log (\operatorname{Inc})$ \\
\hline \multirow[t]{2}{*}{ Related } & $0.063^{*}$ & $-0.346^{*}$ & $-0.346 *$ & $\Delta$ Related & 0.056 & \\
\hline & $(0.035)$ & $(0.165)$ & $(0.166)$ & & $(0.030)$ & \\
\hline \multirow[t]{2}{*}{ Related*Business } & 0.039 & 0.042 & 0.060 & $\Delta$ Related*Business & -0.031 & \\
\hline & $(0.058)$ & $(0.056)$ & $(0.058)$ & & $(0.048)$ & \\
\hline \multirow[t]{2}{*}{ Related*Science } & $0.229^{*}$ & $0.223^{*}$ & $0.243^{*}$ & $\Delta$ Related*Science & $0.098^{* *}$ & \\
\hline & $(0.051)$ & $(0.052)$ & $(0.056)$ & & $(0.055)$ & \\
\hline \multirow[t]{2}{*}{ Major GPA } & $0.064^{*}$ & 0.000 & -0.027 & Into Related & & $0.153^{*}$ \\
\hline & $(0.020)$ & $(0.093)$ & $(0.047)$ & & & $(0.044)$ \\
\hline \multirow[t]{2}{*}{ Related*Major GPA } & & $0.093^{*}$ & 0.084 & Into Related*Business & & 0.010 \\
\hline & & $(0.046)$ & $(0.053)$ & & & $(0.077)$ \\
\hline \multirow[t]{2}{*}{ SAT Math/100 } & $0.041^{*}$ & 0.030 & 0.029 & Into Related*Science & & $0.188^{*}$ \\
\hline & $(0.011)$ & $(0.026)$ & $(0.025)$ & & & $(0.083)$ \\
\hline \multirow[t]{2}{*}{ Related*SAT Math/100 } & & 0.015 & -0.000 & Exit Related & & 0.059 \\
\hline & & $(0.028)$ & $(0.028)$ & & & $(0.048)$ \\
\hline \multirow[t]{2}{*}{ SAT Verbal/100 } & $-0.042^{*}$ & -0.047 & $-0.055^{* *}$ & Exit Related*Business & & 0.008 \\
\hline & $(0.013)$ & $(0.032)$ & $(0.034)$ & & & $(0.070)$ \\
\hline \multirow[t]{2}{*}{ Related*SAT Verbal/100 } & & 0.007 & 0.012 & Exit Related*Science & & -0.056 \\
\hline & & $(0.034)$ & $(0.036)$ & & & $(0.081)$ \\
\hline \multirow[t]{2}{*}{ Non-Major GPA } & & & 0.049 & Graduate Degree & $0.206^{*}$ & $0.198^{*}$ \\
\hline & & & $(0.034)$ & & $(0.028)$ & $(0.028)$ \\
\hline \multirow[t]{2}{*}{ Related*Non-Major GPA } & & & 0.024 & & & \\
\hline & & & $(0.040)$ & & & \\
\hline \multirow[t]{2}{*}{ Graduate Degree } & 0.027 & 0.022 & 0.022 & & & \\
\hline & $(0.028)$ & $(0.028)$ & $(0.028)$ & & & \\
\hline Year Effects & $\mathrm{Y}$ & $\mathrm{Y}$ & $\mathrm{Y}$ & & $\mathrm{Y}$ & $\mathrm{Y}$ \\
\hline Occupation Effects & $\mathrm{N}$ & $\mathrm{N}$ & $\mathrm{N}$ & & $\mathrm{Y}$ & $\mathrm{Y}$ \\
\hline Major Effects & $\mathrm{Y}$ & $\mathrm{Y}$ & $\mathrm{Y}$ & & $\mathrm{Y}$ & $\mathrm{Y}$ \\
\hline Additional Ability Controls & $\mathrm{N}$ & $\mathrm{N}$ & $\mathrm{N}$ & & $\mathrm{Y}$ & $\mathrm{Y}$ \\
\hline $\mathrm{N}$ & 4,927 & 4,927 & 4,675 & & 2,843 & 2,843 \\
\hline
\end{tabular}


Table 7: Model Validation - Perfect Information - Summary Statistics

\begin{tabular}{lcc|cc|cc} 
& \multicolumn{2}{c|}{ Business Majors } & \multicolumn{2}{c|}{ Science Majors } & \multicolumn{2}{c}{ Other Majors } \\
\hline & Data & Model & Data & Model & Data & Model \\
\% Selected & 26.1 & 26.2 & 24.7 & 25.6 & 49.2 & 48.2 \\
SAT Math & 529 & 536 & 596 & 579 & 525 & 531 \\
Verbal Residual & -12.0 & -13.4 & -7.9 & -11.3 & 10.4 & 13.6 \\
& & & & & & \\
\% Job is Related & 78.4 & 78.0 & 79.8 & 78.7 & 61.0 & 61.3 \\
\% Pink Collar & 13.6 & 15.3 & 14.6 & 13.8 & 39.3 & 40.0 \\
\% White Collar & 54.4 & 52.9 & 66.0 & 64.2 & 29.7 & 28.6 \\
\% Graduate Degree & 20.2 & 24.4 & 36.4 & 31.7 & 26.4 & 29.2
\end{tabular}

Table 8: Model Validation - Perfect Information - Wage Regressions

\begin{tabular}{lcc|cc|cc} 
& Data & Model & Data & Model & Data & Model \\
\hline Business & 0.19 & 0.18 & 0.19 & 0.17 & 0.14 & 0.10 \\
Science & 0.23 & 0.24 & 0.21 & 0.21 & 0.02 & 0.08 \\
Job is Related & & & & & 0.06 & 0.07 \\
Related x Bus. & & & & & 0.04 & 0.08 \\
Related x Sc. & & & & & 0.23 & 0.15 \\
SAT Math/100 & & & 0.02 & 0.03 & 0.02 & 0.03 \\
SAT Verbal/100 & & & -0.04 & -0.04 & -0.04 & -0.03 \\
Major GPA & & & 0.07 & 0.04 & 0.06 & 0.04 \\
\hline Year/Grad controls & $\mathrm{Y}$ & $\mathrm{Y}$ & $\mathrm{Y}$ & $\mathrm{Y}$ & $\mathrm{Y}$ & $\mathrm{Y}$
\end{tabular}


Table 9: Model Validation - Imperfect Information - Summary Statistics

\begin{tabular}{lcc|cc|cc} 
& \multicolumn{2}{c|}{ Business Majors } & \multicolumn{2}{c|}{ Science Majors } & \multicolumn{2}{c}{ Other Majors } \\
\hline & Data & Model & Data & Model & Data & Model \\
\% Selected & 26.1 & 29.4 & 24.7 & 25.6 & 49.2 & 45.1 \\
SAT Math & 529 & 534 & 596 & 571 & 525 & 532 \\
Verbal Residual & -12.0 & -14.3 & -7.9 & -8.4 & 10.4 & 12.5 \\
& & & & & & \\
\% Job is Related & 78.4 & 78.1 & 79.8 & 76.3 & 61.0 & 55.3 \\
\% Pink Collar & 13.6 & 15.0 & 14.6 & 19.7 & 39.3 & 33.4 \\
\% White Collar & 54.4 & 53.0 & 66.0 & 57.6 & 29.7 & 33.2 \\
\% Graduate Degree & 20.2 & 24.6 & 36.4 & 33.6 & 26.4 & 31.5
\end{tabular}

Table 10: Model Validation - Imperfect Information - Wage Regressions

\begin{tabular}{lcc|cc|cc} 
& Data & Model & Data & Model & Data & Model \\
\hline Business & 0.19 & 0.08 & 0.19 & 0.09 & 0.14 & 0.05 \\
Science & 0.23 & 0.13 & 0.21 & 0.12 & 0.02 & -0.08 \\
Job is Related & & & & & 0.06 & 0.09 \\
Related x Bus. & & & & & 0.04 & 0.03 \\
Related x Sc. & & & & & 0.23 & 0.23 \\
SAT Math/100 & & & 0.02 & 0.03 & 0.02 & 0.03 \\
SAT Verbal/100 & & & -0.04 & -0.02 & -0.04 & -0.02 \\
Major GPA & & & 0.07 & 0.09 & 0.06 & 0.07 \\
\hline Year/Grad controls & $\mathrm{Y}$ & $\mathrm{Y}$ & $\mathrm{Y}$ & $\mathrm{Y}$ & $\mathrm{Y}$ & $\mathrm{Y}$
\end{tabular}


Table 11: Returns to College Major - Perfect Information

\begin{tabular}{lc|cccc} 
& OLS & All & Business & Science & Other \\
\hline Business & & & & & \\
& 0.19 & 0.04 & 0.12 & 0.03 & -0.01 \\
Science & 0.23 & 0.08 & 0.07 & 0.15 & 0.05 \\
\hline & & & & & \\
Year/Grad controls & Y & Y & Y & Y & Y
\end{tabular}

Table 12: Returns to College Major - Imperfect Information

\begin{tabular}{lc|cccc} 
& OLS & All & Business & Science & Other \\
\hline Business & 0.08 & 0.10 & 0.11 & 0.10 & 0.08 \\
& & & & & \\
Science & 0.13 & 0.12 & 0.13 & 0.14 & 0.11 \\
\hline & & & & & \\
Year/Grad controls & Y & Y & Y & Y & Y
\end{tabular}


Table 13: Log-Wage Decomposition - Perfect Information

\begin{tabular}{lc|ccc} 
& All & Business & Science & Other \\
\hline Wages & & & & \\
Mean & 10.50 & 10.57 & 10.63 & 10.40 \\
Standard Deviation & 0.63 & 0.60 & 0.57 & 0.65 \\
& & & & \\
General HC & & & & \\
Mean & 10.08 & 10.20 & 10.17 & 9.96 \\
Standard Deviation & 0.32 & 0.34 & 0.29 & 0.29 \\
& & & & \\
Specific HC & & & & \\
Mean & 0.02 & -0.03 & 0.06 & 0.02 \\
Standard Deviation & 0.12 & 0.15 & 0.15 & 0.06
\end{tabular}

Table 14: Log-Wage Decomposition- Imperfect Information

\begin{tabular}{lc|ccc} 
& All & Business & Science & Other \\
\hline Wages & & & & \\
Mean & 10.50 & 10.52 & 10.57 & 10.44 \\
Standard Deviation & 0.62 & 0.59 & 0.61 & 0.64 \\
& & & & \\
General HC & & & & \\
Mean & 10.08 & 10.18 & 10.09 & 10.00 \\
Standard Deviation & 0.31 & 0.33 & 0.31 & 0.28 \\
& & & & \\
Specific HC & & & & \\
Mean & 0.02 & -0.05 & 0.09 & 0.02 \\
Standard Deviation & 0.19 & 0.16 & 0.29 & 0.08
\end{tabular}

